Article

\title{
Humanization of Drosophila Goo to Model GNAO1 Paediatric Encephalopathies
}

\author{
Mikhail Savitsky ${ }^{1}\left(\mathbb{D}\right.$, Gonzalo P. Solis $^{1}\left[{ }^{1}\right.$, Mikhail Kryuchkov $^{1}$ and Vladimir L. Katanaev ${ }^{1,2, *(\mathbb{D})}$ \\ 1 Translational Research Center in Oncohaematology, Department of Cell Physiology and Metabolism, \\ Faculty of Medicine, University of Geneva, 1211 Geneva, Switzerland; mikhail.savitskiy@unige.ch (M.S.); \\ gonzalo.solis@unige.ch (G.P.S.); Mikhail.Kryuchkov@unige.ch (M.K.) \\ 2 School of Biomedicine, Far Eastern Federal University, 690690 Vladivostok, Russia \\ * Correspondence: vladimir.katanaev@unige.ch
}

Received: 24 August 2020; Accepted: 2 October 2020; Published: 6 October 2020

\begin{abstract}
Several hundred genes have been identified to contribute to epilepsy—the disease affecting 65 million people worldwide. One of these genes is GNAO1 encoding G $\alpha_{0}$, the major neuronal $\alpha$-subunit of heterotrimeric $G$ proteins. An avalanche of dominant de novo mutations in GNAO1 have been recently described in paediatric epileptic patients, suffering, in addition to epilepsy, from motor dysfunction and developmental delay. Although occurring in amino acids conserved from humans to Drosophila, these mutations and their functional consequences have only been poorly analysed at the biochemical or neuronal levels. Adequate animal models to study the molecular aetiology of GNAO1 encephalopathies have also so far been lacking. As the first step towards modeling the disease in Drosophila, we here describe the humanization of the Goo locus in the fruit fly. A two-step

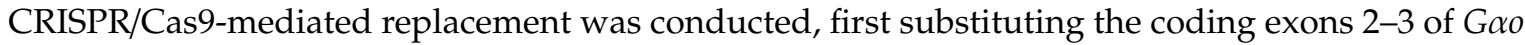
with respective human GNAO1 sequences. At the next step, the remaining exons 4-7 were similarly replaced, keeping intact the gene Cyp49a1 embedded in between, as well as the non-coding exons, exon 1 and the surrounding regulatory sequences. The resulting flies, homozygous for the humanized GNAO1 loci, are viable and fertile without any visible phenotypes; their body weight, locomotion, and longevity are also normal. Human G $\alpha_{\mathrm{O}}$-specific antibodies confirm the endogenous-level expression of the humanized $\mathrm{G} \alpha \mathrm{o}$, which fully replaces the Drosophila functions. The genetic model we established will make it easy to incorporate encephalopathic GNAO1 mutations and will permit intensive investigations into the molecular aetiology of the human disease through the powerful toolkit of Drosophila genetics.
\end{abstract}

Keywords: paediatric encephalopathy; GNAO1; G protein; humanization; Drosophila; disease model

\section{Introduction}

Epilepsy is a chronic disease of multigenic origin, characterized by appearance, mostly in an unpredicted manner, of seizures, and sometimes complicated by other neurological or neurodevelopmental deficits [1]. Seizures result from an imbalance between the inhibitory and excitatory conductance in the brain and can be induced by acute toxic or traumatic impacts. The causes of the episodic shifts in the balance of inhibition and excitation seen in the chronic epilepsy remain largely unexplained. With 65 millions of people worldwide currently suffering from epilepsy and the inadequacy of the current pharmacological approaches to certain subtypes of the disease, the need to advance our understanding of the aetiology of this disease is clear, as is the urgency to develop novel medical treatments [2].

Several hundred genes linked to epilepsy have been identified [3], and the estimate tells that this number will increase by folds, matching the number of genes linked to cancer and exceeding 
the diversity of the cancer-related genes by biological functions [4,5]. Advances have been made in the understanding of the epileptic molecular and cellular mechanisms and pathways (involving ion channels and their regulators, but also neuronal migration, synaptic plasticity, and neurite outgrowth, among other things $[1,4,6])$. However, many of the epileptic mutations remain enigmatic-both in the sense of how they provoke the disease, as well as in the sense of the broader molecular pathway, hijacked in epilepsy, of which they are part. One of the proteins that have recently emerged as an important player in epilepsy is G $\alpha_{0}$ - the major neuronal $\alpha$-subunit of heterotrimeric G proteins, encoded by the gene GNAO1. Starting from 2013 [7], whole-exome sequencing in a subset of epileptic patients has resulted in an avalanche of described mutations in GNAO1 (see [8] for the most up to date review). This subset represents paediatric patients with the early onset epileptic encephalopathy and Ohtahara syndrome, suffering additionally from movement disorders and developmental delays. These patients are resistant to conventional antiepileptic pharmacological treatments and may die early in life. A number of sites in G $\alpha$ o have been found mutated in these epileptic patients, all affecting amino acids conserved among $G \alpha_{0}$ and its orthologues all the way down to fruit flies and nematodes (Figure 1A), highlighting the importance of the affected amino acids for the G $\alpha_{0}$ function. GNAO1 mutations in epilepsy are heterozygous, suggesting their dominant nature. Interestingly, the relative degree of manifestation of different deficits (seizures, developmental delay, movement disorders) may be different depending on the exact amino acid mutation in G $\alpha_{0}$ [9-11]. Recently, a point mutation in $\mathrm{G} \alpha \mathrm{o}$ was also identified to cause a severe childhood speech disorder [12].

Heterotrimeric $G$ proteins are key signalling molecules best recognized as the immediate transducers of GPCRs (G-protein-coupled receptors). Coupled to GPCRs, heterotrimeric G proteins transduce signals from a large variety of extracellular cues, from quanta of light, ions, small organic molecules, to large macromolecules [13]. A heterotrimeric $G$ protein complex consists of three subunits, $\alpha, \beta$, and $\gamma$, of which the $\alpha$-subunit is responsible for binding to guanine nucleotides as well as to the cognate GPCR. Sixteen vertebrate $G \alpha$ subunits are classified into four major families

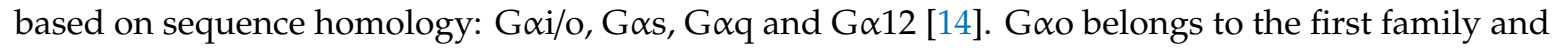
transduces the signal of a group of rhodopsin-like GPCRs, including the opioid, $\alpha 2$-adrenergic, D2 dopaminergic, M2 muscarinic, and somatostatin receptors [15]. G $\alpha_{0}$ was among the first $\alpha$-subunits discovered [16] and found to be the major G $\alpha$ subunit of the central nervous system (CNS) across the animal kingdom $[17,18]$, controlling both development and adult physiology of the brain $[19,20]$. G $\alpha \mathrm{o}$ knockout $(\mathrm{KO})$ mice showed a strong developmental delay during the first 3 weeks after birth and a short half-life of only 7 weeks on average [20]. G $\propto$ o KO mice also presented multiple neurological abnormalities such as hyperalgesia, hyperactivity, generalized tremor with occasional seizures, and a severe impairment of motor control $[19,20]$. At the cellular level, dorsal root ganglion cells derived from $\mathrm{G} \alpha_{\mathrm{O}} \mathrm{KO}$ mice presented a reduced inhibition of $\mathrm{Ca}^{2+}$ channel currents by the agonist-induced activation of opioid receptors [20]. G $\alpha$ o has also been implicated in the regulation of $\mathrm{Ca}^{2+}$ and $\mathrm{K}^{+}$ channels in sensory and hippocampal neurons $[19,21]$. In addition to neurons, $G \alpha_{0}$ is expressed in the heart [22], where it is necessary for proper development and functioning of the organ $[23,24]$. G $\alpha_{\mathrm{o}}$ has additional developmental functions such as cell fate determination and polarization, in part via the Wnt-Frizzled pathway $[25,26]$, as well as pathological implications, e.g., in cancer $[27,28]$. 
A

H.sapiens
M.musculus
D.rerio
D.melanogster
C.elegans
H.sapiens
M.musculus
D.rerio
D.melanogster
C.elegans

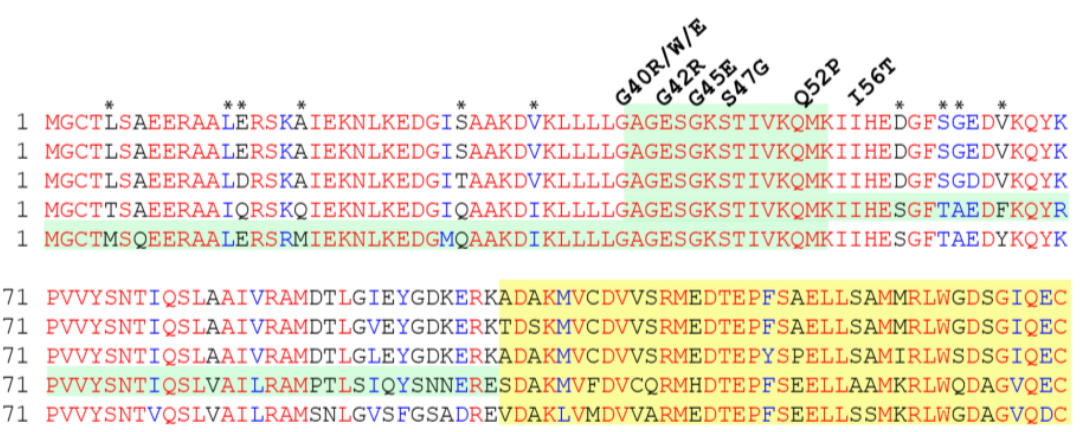

$$
\hat{\nu}^{00} \hat{\vartheta}^{0}
$$

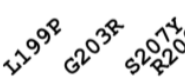

141 FNRSREYQLNDSAKYYLDS̈LDRIGAADYQPTEQDILRTRVKTTGIVETHFTFKNLHFRLFDVGGQRSERK $\begin{array}{lll}\text { M.musculus } & 141 & \text { FNRSREYQLNDSAKYYLDSLDRIGAGDYQPTEQDILRTRVKTTGIVETHFTFKNLHFRLFDVGGQRSERK } \\ \text { D.rerio } & 141 & \text { FSRAREYQLNDSAQYYLSLDRIGAADYQPTEQDILRTRVKTTGIVETHFTFKNLHFRLFDVGGQRSERK } \\ \text { D.melanogster } & 141 \text { FSRSNEYQLNDSAKYFLDDLDRLGAKDYQPTEQDILRTRVKTTGIVEVHFSFKNLNFKLFDVGGQRSERK }\end{array}$ $\begin{array}{lll}\text { M.musculus } & 141 & \text { FNRSREYQLNDSAKYYLDSLDRIGAGDYQRTEQDILRTRVKTTGIVETHFTFKNLHFRLFDVGGQRSERK } \\ \text { D.rerio } & 141 \text { FSRAREYQLNDSAQYYLSLDRIGAADYQPTEQDILRTRVKTTGIVETHFTFKNLHFRLFDVGGQRSERK } \\ \text { D.melanogster } & 141 \text { FSRSNEYQLNDSAKYFLDDLDRLGAKDYQRTEQDILRTRVKTTGIVEVHFSFKNLNFKLFDVGGQRSERK }\end{array}$ $\begin{array}{llll}\text { D.melanogster } & 141 \text { FSRSNEYQLNDSAKYFLDDLDRLGAKDYQPTEQDILRTRVKTTGIVEVHFSFKNLNFKLFDVGGQRSERK } \\ \text { C.elegans } & 141 \text { FSRSNEYOLNDSAKYFLDDLERLGEAIYOPTEODILRTRVKTTGIVEVHFTFKNLNFKLFDVGGORSERK }\end{array}$

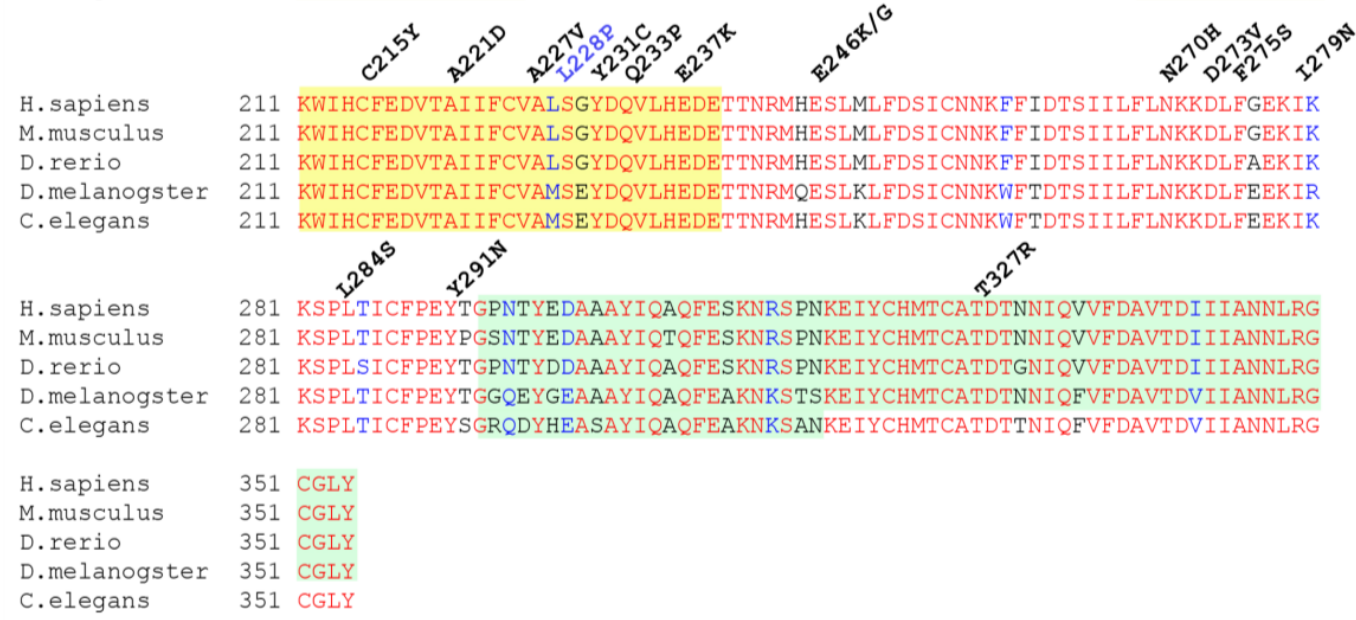

\section{B}

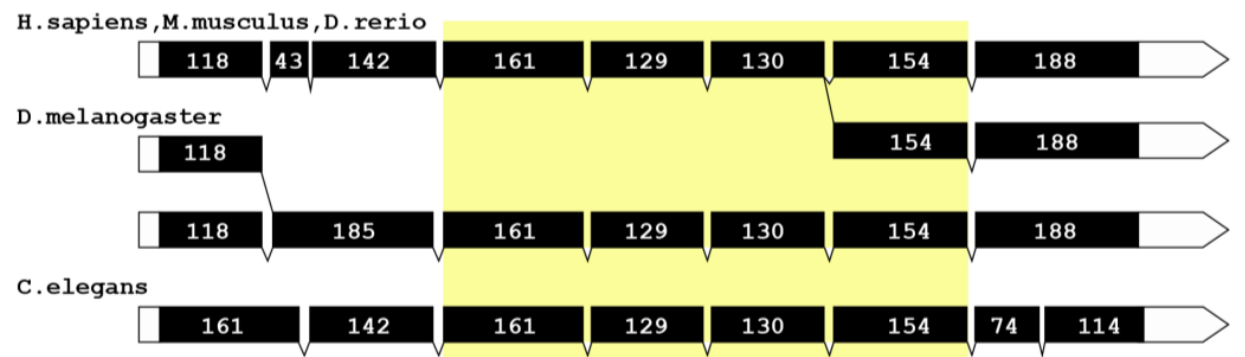

Figure 1. (A) Alignment of $G \alpha_{0}$ homologs from three vertebrate and two invertebrate organisms. Pale green and yellow colours on the background of the alignment mark the exon boundaries. Above the alignment, the known mutations associated with human neurological phenotypes are designated. The mutated amino acids belong to conservative parts of proteins (letter blocks of red). The mismatching amino acids that were not replaced during the editing of $\mathrm{dG} \alpha_{\mathrm{o}}$ are designated with asterisks. For Drosophila, the dG $\alpha_{0}-\mathrm{B}$ isoform is shown. (B) Schematic exon-intron structures of G $\alpha_{0}$ homologs. Black boxes mark the coding parts of the exons, and white boxes indicate the noncoding parts. The drawing of the exons is presented in scale. Digits inside the exons mark their precise length in base pairs. The yellow box marks identical exons in the species compared.

G $\alpha$ o expression was found to strongly increase during early neonatal rat brain development [29], where it is enriched in growth cones [30]. In the rat pheochromocytoma cell line PC12, G $\alpha$ o expression 
rises during the process of neurite outgrowth induced by nerve growth factor (NGF) [31-33], and overexpression of a G $\alpha$ o active mutant potentiates the effects of NGF in neurite length [34]. Similar to its mammalian counterpart, insect G $\alpha_{0}$ is strongly expressed in the CNS of the adult Drosophila [18]. G $\alpha$ o transcript and protein were present at all stages of embryonic development with a marked increase during the period of active axonogenesis [35,36]. These early data suggested that $\mathrm{G} \alpha \mathrm{o}$ may be involved in neuronal differentiation, a role supported by later studies showing reduced neurogenesis and increased cell death in the olfactory bulb of G $\alpha_{0} \mathrm{KO}$ mice [37] and defects in guidance and axonal growth of motoneurons in G $\alpha$ o mutant fruit flies [23]. Additionally, differentiation of mouse embryonic stem cells into dopaminergic neurons pointed to $G \alpha_{0}$ as one of the genes specifically upregulated during neurogenesis [38].

Driven by the pivotal roles of $G \alpha_{0}$ and by the fact that the list of its molecular targets was remarkably short [39], we have performed massive whole genome/proteome screenings to identify novel $G \alpha o$ interaction partners. This analysis identified $>250$ proteins as novel candidate $G \alpha_{0}$ partners. "Cherry-picking" of individual proteins from this list resulted in detailed descriptions of novel mechanisms of G $\alpha_{0}$-controlled regulation of Wnt/Frizzled signalling, neuromuscular junction formation, planar cell polarity, asymmetric cell divisions, etc. [40-45]. As opposed to such characterizations of selected individual $G \alpha o$ partners, we next aimed at identifying functional modules within the $\mathrm{G} \alpha$ o interactome. Several functional modules (such as cytoskeleton organization, cell division, cell adhesion, etc.) were identified within the G $\alpha_{0}$ interactome; subsequent work identified $\mathrm{G} \alpha \mathrm{o}$ as a master regulator of vesicular trafficking [46]. Remarkably, across different cell types (neuronal, mesenchymal, epithelial) and species (insects and mammals), G $\alpha$ o is found to dually localize to PM (plasma membrane) and Golgi $[46,47]$. This dual localization is found to play a coordinated role in the formation of cellular protrusions (such as neurites in neuronal cells), so that the PM pool of $G \alpha o$ entices the initiation of the protrusion, while the Golgi pool ensures material delivery to it, permitting its elongation and stabilization. In the nervous system, these novel G $\alpha$ o activities are necessary not only for neuritogenesis, but also for synaptogenesis [46]. As improper synaptic plasticity and process outgrowth are both implicated in the aetiology of epilepsy [1], the possible dominant effects of the epileptic G $\alpha$ o mutations on these novel Golgi-emanating mechanisms discovered by us need to be investigated in detail, as are the molecular events happening at PM. Furthermore, with several established epileptic mutations affecting proteins working in Golgi-mediated trafficking (EpilepsyGene. Available online: http://www.wzgenomics.cn/EpilepsyGene/ (accessed on 05.10.2020)), and likely more to emerge, such an investigation could be the entry point into the identification of a novel epileptic pathway, involving G $\alpha 0$-mediated trafficking routes.

Of the point mutations identified within the coding region of GNAO1 in paediatric encephalopathy patients, all correspond to highly conserved residues (Figure 1A), indicating their involvement in basic $\mathrm{G} \alpha \mathrm{o}$ functions. However, the molecular characterization of these mutants has so far been very limited and provides somewhat contradicting findings on the mutant protein expression in heterologous cells, the effects of the mutants on basal and norepinephrine-induced N-type calcium channels, and on the forskolin-stimulated cAMP production $[7,48]$. Thus, the molecular mechanism(s) of G $\alpha$ o mutants in the development of the severe neurological disorders await the much-needed detailed clarification to reveal potential therapeutic targeting approaches.

Animal models have the instrumental role in deciphering the disease mechanisms and in identifying/validating the treatment routes. Drosophila has been used to model a variety of human maladies, especially neurological ones [49-54]. As the first step towards modeling GNAO1 paediatric encephalopathies in the fruit fly, we here describe the humanization of the Drosophila $\mathrm{G} \alpha$ o locus, finding the human protein fully replaces the insect one's functions without any aberrations. 


\section{Materials and Methods}

\subsection{Plasmids}

\subsubsection{Donor Plasmid pLdhGao23R for the First Round of Humanization dG $\alpha$ o}

Synthesis of the DNA fragment of humanized Drosophila G $\alpha o$ containing exons 2 and 3 with the intron between them was ordered from Synbio Technologies (Monmouth Junction, NJ, USA) as the plasmid pUC57-dhG $\alpha 023$. The synthesized fragment contained nucleotide substitutions in the Drosophila sequence minimally needed to encode the human amino acids. Additionally, synonymous substitutions were introduced in the target sites for the gRNA-Cas9 complex in order to avoid double-strand breaks. The fragment was further designed to contain AarI and EcoRV restriction sites adjoining the exon 2, and an additional AarI site directly after the exon 3.

The left homologous arm (LHA) was PCR amplified with the LHAdG $\alpha$ o23fw and LHAdG $\alpha$ o23rev primers from genomic DNA using Phusion High-Fidelity DNA Polymerase (New England Biolabs, Ipswich USA, cat. \#M0530S), producing a 1060bp PCR product, which was further cloned into the pUC57-dhG $\alpha_{0} 23$ plasmid by the EcoRV site producing the construct pLdhG $\alpha_{0} 23$. The right homologous arm (RHA) was PCR amplified with the RHAdG $\alpha$ o23fw and RHAdG $\alpha \mathrm{o} 23$ rev primers, and the resulting $1070 \mathrm{bp}$ PCR product was cloned into the plasmid pHD-ScarlessDsRed (Drosophila Genomics Resource Center, Bloomington USA, stock \#1364) into the SapI site, producing the construct pScarless-dhG $\alpha$ oR. Both cloning steps were performed with the NEBuilder HiFi DNA Assembly Cloning Kit (New England Biolabs, cat. \#E5520S). The AarI-AarI fragment from pLdhG $\alpha 023$ was cloned into the AarI site of pScarless-dhG $\alpha \mathrm{oR}$. The resultant donor plasmid pLdhG $\alpha \mathrm{o} 23 \mathrm{R}$ contains

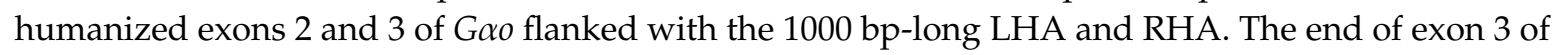
G $\alpha$ o in the plasmid is modified by insertion of the piggyBac transposon between the duplicated TTAA sequence. The precise excision of the piggyBac restores the correct exon sequence with unique TTAA.

\subsubsection{Donor Plasmid for the Second Round of Humanization dG $\alpha \mathrm{o}$}

The DNA fragment of humanized Drosophila Goo containing exons 4 to 7 with introns between them and $120 \mathrm{bp}$ intronic flanking sequences before exon 4 and after exon 7 was synthesized by Synbio Technologies as the plasmid pUC57-dhG $\alpha_{0} 47$. pUC57-dhG $\alpha_{0} 47$ was used as a template for the PCR amplification of two fragments: one with the primer set LHAdG $\alpha_{0} 47 \mathrm{fw} / \mathrm{LHAdG} \alpha_{0} 47 \mathrm{rev}$ and the other with the primer set RHAdG $\alpha_{0} 47 \mathrm{fw} / \mathrm{RHAdG} \alpha 047 \mathrm{rev}$. The $650 \mathrm{bp}$ and $430 \mathrm{bp}$ PCR products amplified, respectively, were mixed with $\mathrm{pHD}$-ScarlessDsRed pre-digested with SapI (New England Biolabs, cat \#R0569S) and AarI (Thermo Fisher Scientific, Waltham. MA, USA, cat. \#ER1581) restriction enzymes and circulated using the NEBuilder HiFi DNA Assembly Cloning Kit. The resultant donor plasmid pLdhG $\alpha$ o47R contains humanized exons 4-7 of G $\alpha$ o flanked with the short 130 bp LHA and RHA and the piggyBac transposon marked with 3xP3-DsRed inserted into the duplicated TTAA sequence in the exon 6.

\subsubsection{Plasmids Providing Expression of gRNAs under the Control of the Drosophila U6:3 Promoter}

CRISPR targets sites were identified using Target Finder [55], targetfinder.flycrispr.neuro.brown. edu/.

Complimentary oligonucleotides GTCGGACTTTAAACAATATCGAC and AAACGTCGATA TTGTTTAAAGTC, GTCGGCCAGCAGCTCCTCCGAGA and AAACTCTCGGAGGAGCTGCTGGC, GTCGTGGCAGGACGCCGGTGTCC and AAACGGACACCGGCGTCCTGCCA, GTCGGCAAACAA CCTGCGCGGCTG and AAACCAGCCGCGCAGGTTGTTTGC, GTCGGACCACTCACCTGTGTATT and AAACAATACACAGGTGAGTGGTC, GTCGTTTCCTGGACGATTTGGAT and AAACATCCAA ATCGTCCAGGAAA were annealed and cloned into pCFD3-dU6:3gRNA (Addgene, Watertown USA, cat. \#49410), which was digested with BbsI (New England Biolabs, cat. \#R0539S). A total of 6 plasmids from pCFD-gRNA1 to pCFD-gRNA6 were constructed. Set plasmids pCFD-gRNA1, 
pCFD-gRNA2, pCFD-gRNA3 combined with the donor plasmid pLdhG $\alpha 023 R$ were used for the first round of transgenesis; pCFD-gRNA4, pCFD-gRNA5, pCFD-gRNA6 together with the donor plasmid hdG $\alpha_{0} 47$ ScarlessDsRed-for the second one.

\subsection{Flies, Germline Transformation}

Flies were maintained at $25{ }^{\circ} \mathrm{C}$ on the standard medium. The strain $y[1] s c\left[{ }^{*}\right] v[1] \mathrm{sev}[21]$; $P\{y[+t 7.7] v[+t 1.8]=n o s-C a s 9 . R\} a t t P 2$ expressing Cas9 in the germline under the control of the nos promoter (Bloomington Drosophila Stock Center (BDSC, Bloomington USA), stock \#78782) was used for germline transformation in the first round of transgenesis. The resultant fly stock Goo[h23ex4aa-1] was combined with $P\{y[+t 7.7] v[+t 1.8]=n o s-C a s 9 . R\} a t t P 2$ and used for the second round of transgenesis. The strain w[1118]; In(2LR)Gla, wg[Gla-1]/CyO; Herm\{3xP3-ECFP,alphatub-piggyBacK10\}M10 expressing PiggyBac transposase (BDSC, stock \# 32073) was used for the excision of the PiggyBac-based marker. The resultant alleles and their derivatives were balanced over $\mathrm{CyO}$.

Germline transformation was performed as described in the Gompel's lab protocol (Drosophila germline transformation. Available online: gompel.org/wp-content/uploads/2015/12/Drosophilatransformation-with-chorion.pdf (accessed on 05.10.2020)). Embryos were injected with the donor plasmid (500 ng/ $\mu \mathrm{L}$ ) and three gRNA plasmids (100 ng/ $\mu \mathrm{L}$ each).

Transformants were selected under a fluorescence stereomicroscope (Zeiss SteReEO Discovery.V8, Carl Zeiss, Jena Germany) using the Filter Set 43 HE for DsRed fluorescent dye detection (excitation BP 550/25; emission BP 605/70).

\subsection{Molecular Analysis}

Genomic DNA was isolated from individual flies of different genotypes as described previously [56]. PCR analysis was carried out with different primer sets (Supplementary Table S1, Figure 2B) using Phusion High-Fidelity DNA Polymerase following the manufacturer's instructions.

Total RNA was isolated with the NucleoSpin RNA kit (Macherey-Nagel, Dueren Germany) from 30 adult flies for each sample. cDNA was synthesized by priming with oligo-dT with RevertAid Reverse Transcriptase (Thermo Fisher Scientific, cat. \#EP0441) following the manufacturer's instructions. The $958 \mathrm{bp}$ PCR products including the region from exon 2 to exon 7 were amplified from cDNA with the primers dG $\alpha$ omRNAfw and dG $\alpha$ omRNArev.

\subsection{Immunochemistry and Microscopy}

The following primary antibodies were used: mouse monoclonal antibody against bovine G $\alpha$ o (1:20 dilution, Santa Cruz Biotechnology, Dallas USA, cat. \#sc-13532) and rabbit anti-dG $\alpha 0$ (1:50; [40]). Secondary antibodies were donkey anti-mouse Cy3 and donkey anti-rabbit 488 (Jackson ImmunoResearch, West Grove USA, cat. \#715-165-150 and \#711-545-152), used at the 1:300 dilution.

Ventral nerve cords and brains from third instar larvae were fixed with $4 \%$ paraformaldehyde in PBS, permeabilized in $0.5 \%$ NP-40 and immunostained in $0.2 \%$ Tween 20 in PBS. Coverslips were finally mounted with Vectashield (Vector Labs, Burlingame USA, cat. \#H-1000-10) for microscopy analysis. Humanized and wild-type (control) larval tissues were stained simultaneously in the same vial in order to control the immunostaining specificity.

Fluorescent images were acquired with a Zeiss LSM 800 Airyscan confocal microscope and the images were reconstructed from Z-stacks using ZEN blue software (Carl Zeiss). All images were processed using the same confocal settings. 


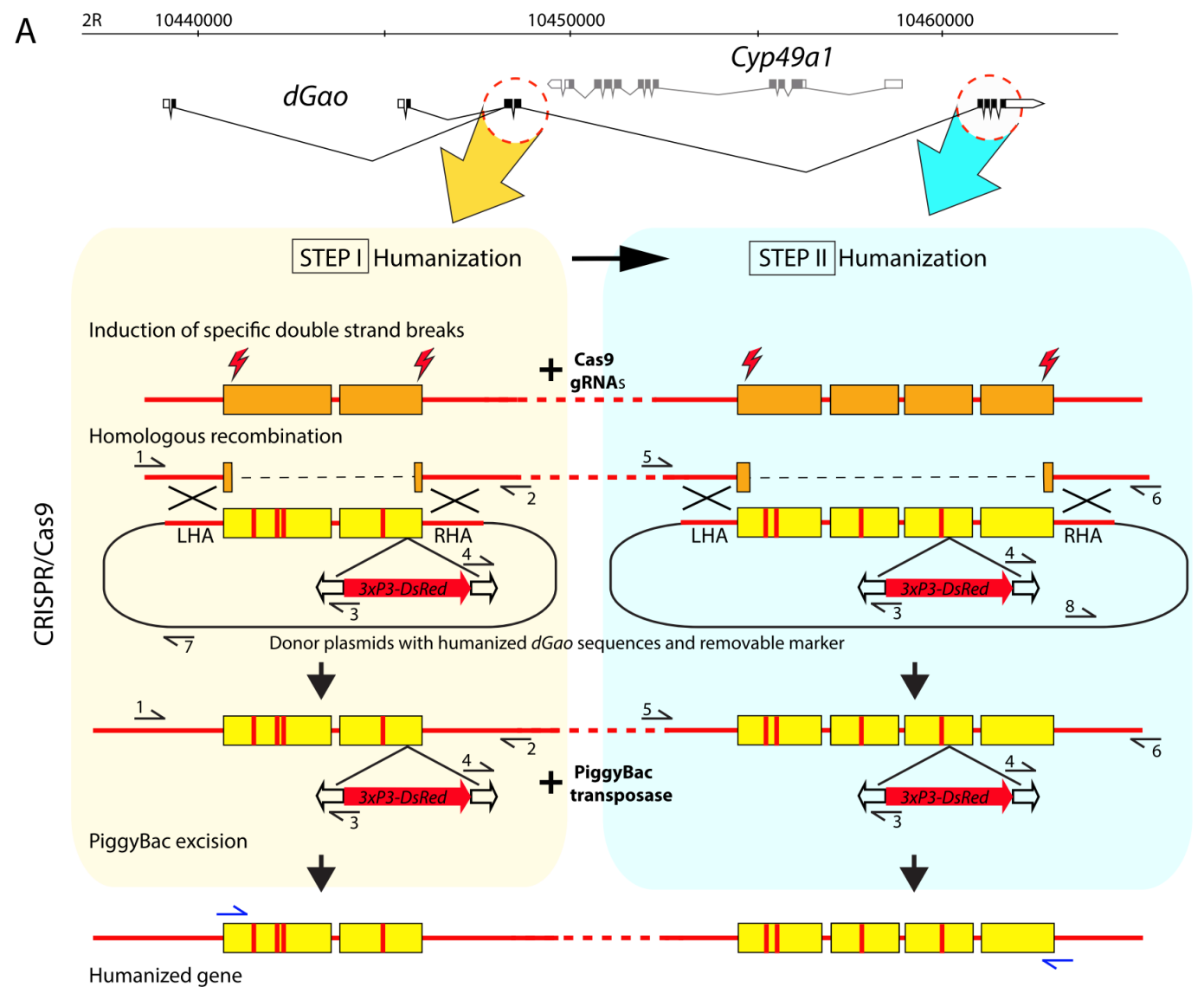

B
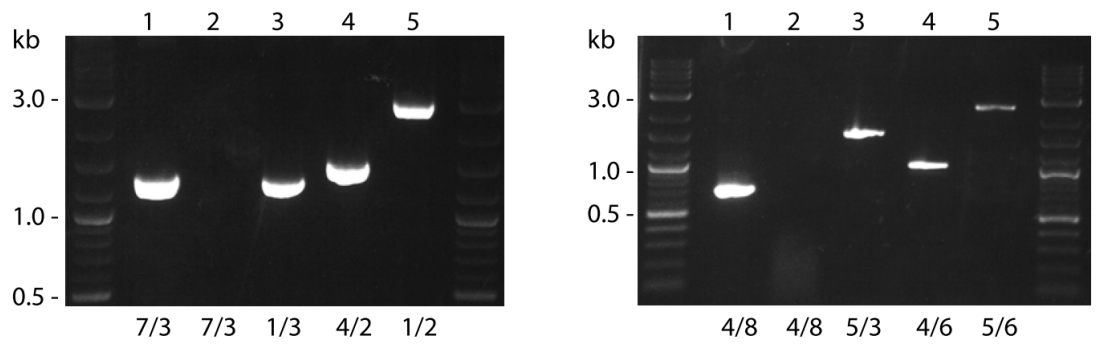

Figure 2. (A) Two-step strategy for genomic humanization of $d G \alpha_{0}$. The primers for validation of the correct donor sequence integration in the genome are designated with black horizontal arrows and marked with digits. Primers used in RT-PCR are designated with blue horizontal arrows. LHA and RHA: left and right homologous arms in the donor plasmids required for homologous recombination with the genomic sequences. The exons with vertical red lines schematically designate humanized sequences with mismatches. (B) Agarose gels with PCR products obtained with the primers as numbered below each lane (see Supplementary Table S1 for sequences). Lanes 1: control PCR from donor plasmids pLdhG $\alpha_{0} 23 \mathrm{R}$ (left panel) and pLdhG $\alpha_{0} 47 \mathrm{R}$ (right panel). The absence of a PCR product (lanes 2) performed with the same primers from the genomic DNA of transgenic flies indicates the correct integration of the donor sequences without the plasmid backbone. Lanes 3 and 4: verification of the entire integration of the donor sequence in the genome before excision of the 3xP3-dsRed marker. Lanes 5: PCR through the integrated donor sequence after the excision of the 3xP3-dsRed marker

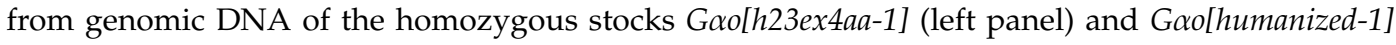
(right panel). 


\subsection{Behavioural Assays}

The negative geotaxis assay was performed as described [57]. In brief, 2-to-5-day-old flies, in groups of 15, males and females separately, were placed in empty polystyrene vials. Post gentle tapping was used to bring the flies to the vial bottom, the vial was placed vertically, and the flies climbing above the $8 \mathrm{~cm}$ distance in $10 \mathrm{~s}$ were counted, producing the climbing pass rate as the percent of total flies. Ten groups were tested for each genotype, each group was tested three times. The aversive phototaxic suppression assay, based on the ability of flies to memorize the association of light stimulus with aversive odour (quinine hydrochloride), was performed as described [57].

\section{Results and Discussion}

Comparative analysis of G $\alpha$ o homologs reveals a high degree of similarity in the amino acid sequences of proteins as well as in the exon-intron structures of the genes encoding them. Even evolutionary distant organisms retain the same nucleotide length of the coding sequences in alternatively spliced transcripts and have the resultingly fixed protein length: 354 aa. However, lengths of the genomic loci vary in a wide range from species to species. In humans, the respective locus extends for $165 \mathrm{~kb}$, in Drosophila-for $28 \mathrm{~kb}$, and in C. elegans-for $4.5 \mathrm{~kb}$ (see the gene links: NCBI, GNAO1. Available online: ncbi.nlm.nih.gov/gene/?term=2775 (accessed on 05.10.2020); FlyBase, dGao. Available online: flybase.org/reports/FBgn0001122 (accessed on 05.10.2020 (also see Figure 2A) and WormBase, goa-1. Available online: wormbase.org/species/c_elegans/gene/WBGene00001648\#0-9f-10, respectively, Supplementary Figure S1). Interestingly, all of them have very similar sets of coding exons (Figure 1B). For example, 191 amino acids between 101aa and 292aa are coded by four exons with the lengths 161, 129, 130 and $154 \mathrm{bp}$ in both invertebrates and humans. The percent of similarity between human and C. elegans G $\alpha$ o proteins is $86.7 \%$, with $82.5 \%$ identity. The Drosophila protein is slightly more similar to the human one: $86.5 \%$ similarity and $83.9 \%$ identity, with only 57 mismatching amino acids out of 354. The alignment of five protein sequences (two highly similar G $\alpha_{0}$ isoforms are encoded from the same gene both in humans and in Drosophila) reveals the presence of conservative and independently evolving blocks, which have not changed through hundreds of millions of years (Figure 1B).

With this level of conservation, it is perhaps not surprising that of the de novo point mutations so far identified in patients suffering from GNAO1 encephalopathies (altogether 34 different point mutations occurring in 27 sites), all but one fall into amino acids identical between human, Drosophila and nematode G $\alpha$ o sequences (Figure 1A). This fact suggests that these amino acids play instrumental functions for the activity of $\mathrm{G} \alpha \mathrm{O}$ and also provides the ground to attempt the modeling of GNAO1 encephalopathy in Drosophila. For the sake of terminology, we will refer to the Drosophila and human genes as G $\alpha 0$ and GNAO1, and to the proteins they encode as $\mathrm{dG} \alpha \mathrm{o}$ and $\mathrm{hG} \alpha \mathrm{o}$, respectively.

Drosophila G $\alpha$ o produces two variants of the protein through alternative splicing of the first coding sequence-containing exons. The six downstream exons are common for both transcripts (Figure 1B). These splice variants differ only in seven amino acids, making them $98 \%$ identical to each other. In a pairwise comparison with the two isoforms, hG $\alpha_{\mathrm{o}}$ is closer to the dG $\alpha_{\mathrm{o}} \mathrm{B}$ isoform (Supplementary Figure S2). Both variants of $\mathrm{dG} \alpha \mathrm{o}$ are expressed at similar levels during the life cycle, with one minor exception: one of the isoforms starts to be transcribed in very early embryos and the other one- $10 \mathrm{~h}$ later [36]. The two alternatively spliced first coding exons are distanced from each other by $6 \mathrm{~kb}$. The six downstream common exons are grouped into two clusters with 2 and 4 exons, which are separated by a long intron containing embedded gene Cyp49a1, oriented in the direction opposite to Goo (Figure 2).

The locus of human GNAO1 contains a duplication of the two last exons, which are spliced alternatively to produce two protein isoforms ( $\mathrm{hG} \alpha \mathrm{oA}$ and $\mathrm{hG} \alpha \mathrm{oB})$ with amino acids variations in the C-terminus. In a pairwise comparison with the two human isoforms, $\mathrm{dG} \alpha \mathrm{o}$ is closer to the $\mathrm{hG} \alpha \mathrm{oB}$ isoform (Supplementary Figure S2). Unlike the two Drosophila isoforms, the two human splice variants of GNAO1 are expressed differently, with hG $\alpha$ oA being the major version expressed [58]. All known mutations (from E246K to Y291N) (Figure 1A) in the alternatively spliced exons 7 and 8 belong to hG $\alpha_{\mathrm{o}} \mathrm{A}$. Thus, we concentrated on this variant in our replacement strategy. 
In order to preserve the endogenous structure of the Gao locus with its potential regulatory elements such as enhancers, promoters, insulators, etc., we developed the strategy of sequential

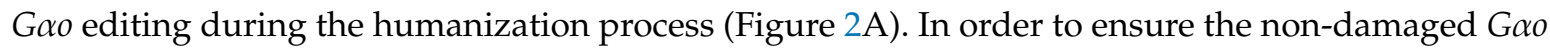

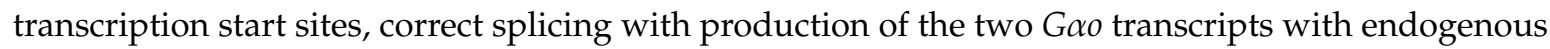
and undamaged 5'UTR sequencing, this strategy involved keeping untouched the non-coding exon together with the first coding exon, which is subject to the alternative splicing. The sequences of the core of the gene were humanized in two steps. In the first step, we humanized the exons 2 and 3 ; in the second-exons 4 to 7 (Figure 2A). Both rounds of transgenesis were performed with the CRISPR-Cas9 technology (see Methods for details). As a template for the homologous recombination, we used donor plasmids containing Drosophila DNA sequences, whereas the codons different between

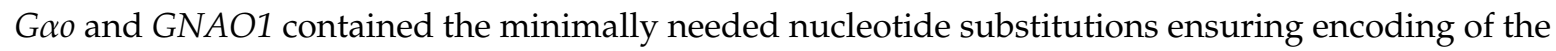
human amino acids. Additionally, the donor plasmid contained synonymous nucleotide substitutions in the sequences corresponding to the Cas9/gRNA complex targets preventing their recognition and destruction by the complex.

For the gene editing, we used the transgenic fly strain expressing Cas9 in the germline. In order to replace the first cluster of exons, we injected embryos with the mixture of four plasmids: the donor plasmid for homologous recombination and three plasmids producing the gRNAs for the induction of breaks in the target genome locus (see Methods). Besides the modified Goo exons and the homologous arms (LHA and RHA), the donor plasmids contained a 3xP3-DsRed marker cassette flanked by the PiggyBac transposon ends inserted in the end of the $3^{\text {rd }}$ exon. Transgenic flies were selected by red fluorescence in eyes provided by the expression of DsRed under the eye-specific 3xP3 promoter [59]. The established transgenic fly strains were verified by PCR with the primers annealing to the neighbouring genomic sequences outside of the homologous arms and inside the PiggyBac transposon. The correct sizes of the PCR products indicated the proper integration of the donor plasmid (Figure 2B). The fly strains with integration of the whole donor plasmid were excluded from the analyses by using primers annealing at the body of plasmid. About one third of the transgenic lines contained the plasmid integrated via the rolling circle replication mechanism and thus had to be discarded.

Three independent transgenic lines with the full set of substitutions, and two independent transgenic lines lacking 4 aa substitutions in the $2^{\text {nd }}$ exon (see below for the explanation on the 4 aa) were identified after the sequencing analysis of the PCR products and selected for further propagation. These fly lines were crossed with the strain encoding the PiggyBac transposase. The excision of the marker gene was identified in the second generation by the loss of red fluorescence in eyes. Since the mobilization of PiggyBac-based transposons is characterized by precise excisions without indels in the insertion site, the integrity of the $3^{\text {rd }}$ exon was restored and, consequently, this partially humanized gene started producing proper transcripts. Finally, three independent strains with the full set of substitutions in the first exon cluster, along with the two independent strains without 4aa substitutions

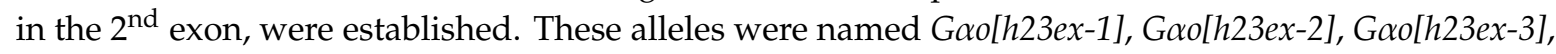

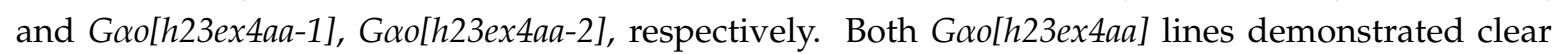
viability and fertility in homozygosity. In a sharp and curious contrast, all the three G $\alpha o[h 23 e x]$ lines were homozygous lethal.

After removing the marker gene, both allele types were confirmed by PCR and sequencing. Then, we extracted total RNA from adult flies, and Goo transcripts were examined through RT-PCR using the primers for the wild-type and mutant alleles. The PCR products amplifying the $958 \mathrm{bp}$ region between the exons 2 and 7 exons were verified by sequencing, revealing that all the mutant transcripts were spliced correctly, and, as expected, that both the wild-type and the mutant transcripts were present in

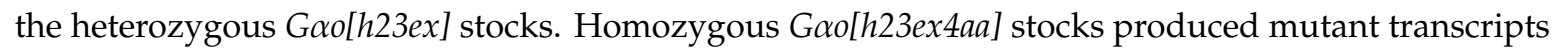
only. Due to the unexplained lethality of the Goo[h23ex] flies, the second round of humanization was performed on the Goo[h23ex4aa-1] strain. 
The second cluster was edited in the same manner as the first one: the Goo[h23ex4aa-1] stock combined with the Cas9-expressing transgene was used for the germline transformation (see Methods). Transgenic flies were selected by the fluorescent marker, and then verified by PCR (Figure 2B) followed by sequencing both before and after the excision of the marker; ultimately, the resultant transcript sequences were also verified. Two independent fly lines obtained through the two-step humanization process were established. In these lines, 26 out of the 27 amino acids different between the human and Drosophila G $\alpha$ o were replaced (except of F156Y, apparently not substituted as a result of gRNA imperfection, adding this non-replaced amino acid to the four not replaced in the first round of

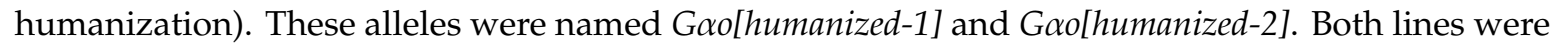
homozygous viable and fertile.

As a result of this two-step CRISPR/Cas9-mediated humanization, we succeeded to replace, in the endogenous $G \alpha o$ locus, 49 amino acids of $\mathrm{dG} \alpha \mathrm{o}$ with the human $\mathrm{G} \alpha \mathrm{o}$ sequences. The resultant identity

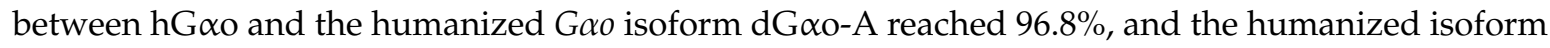
$\mathrm{dG} \alpha_{\mathrm{o}}-\mathrm{B}-97.6 \%$. These values are similar to those between the mouse and human $\mathrm{G} \alpha \mathrm{o}$ sequences and are much higher than within any vertebrate-invertebrate $G \alpha o$ pair.

In addition to the validation of the humanized transcript expression (Figure 2B), we confirmed hG $\alpha$ o expression in the Drosophila central nervous system by immunostaining. Brains together with ventral nerve cords from third instar larvae were probed with antibodies against $\mathrm{dG} \alpha \mathrm{o}$ (polyclonal) and $\mathrm{hG} \alpha_{\mathrm{o}}$ (monoclonal, see Methods). We found that the polyclonal antibodies expectedly recognized both Drosophila and human proteins in our samples, while the monoclonal antibodies had affinity exclusively to the human G $\alpha$ o (Figure 3A). The pattern of immunostaining with different antibodies was identical for both genotypes. These findings support our conclusion that $\mathrm{hG} \alpha_{\mathrm{O}}$ is expressed in a proper way under the endogenous G $\alpha$ o gene regulatory elements. This expression of $h G \alpha o$ was sufficient to fully recapitulate the endogenous functions of $\mathrm{dG} \alpha_{\mathrm{O}}$, as judged by the fertility of the humanized lines and their full viability, measured, e.g., by their normal body weight (Figure 3B) and life span (Figure 3C).

To further verify the completeness of the ability of the humanized G $\alpha_{0}$ to recapitulate the endogenous neuronal $\mathrm{dG} \alpha_{\mathrm{o}}$ functions, we analysed the locomotion and memory performance of the humanized lines. As shown in Figure 3D, the locomotion measured in the negative geotaxis assay [57] revealed equivalent performance of the control and Gxo[humanized-1] lines. Curiously, the Goo[humanized-2] line displayed an increased locomotion in the assay, both in comparison to the control and Gao[humanized-1] line (Figure 3D). While we are currently unable to explain the better performance of this second humanized line, we conclude that the humanization of $\mathrm{dG} \alpha \mathrm{o}$ at least does not impede the locomotor behaviour of the fruit flies, indicating that the sophisticated brain and neuromuscular circuitry needed for the locomotion is functional in the humanized flies. Furthermore, the humanized flies revealed the ability to memorize the association of light (which is normally attractive to Drosophila) with an adverse odour (quinine) in the aversive phototaxic suppression assay [57], proving competence in vision, olfaction, locomotion, learning and memory (M. Savitsky. University of Geneva, 1211 Geneva, Switzerland. Preliminary data). These complex behavioural competences will be important in the modeling of GNAO1 encephalopathy in the future studies. 


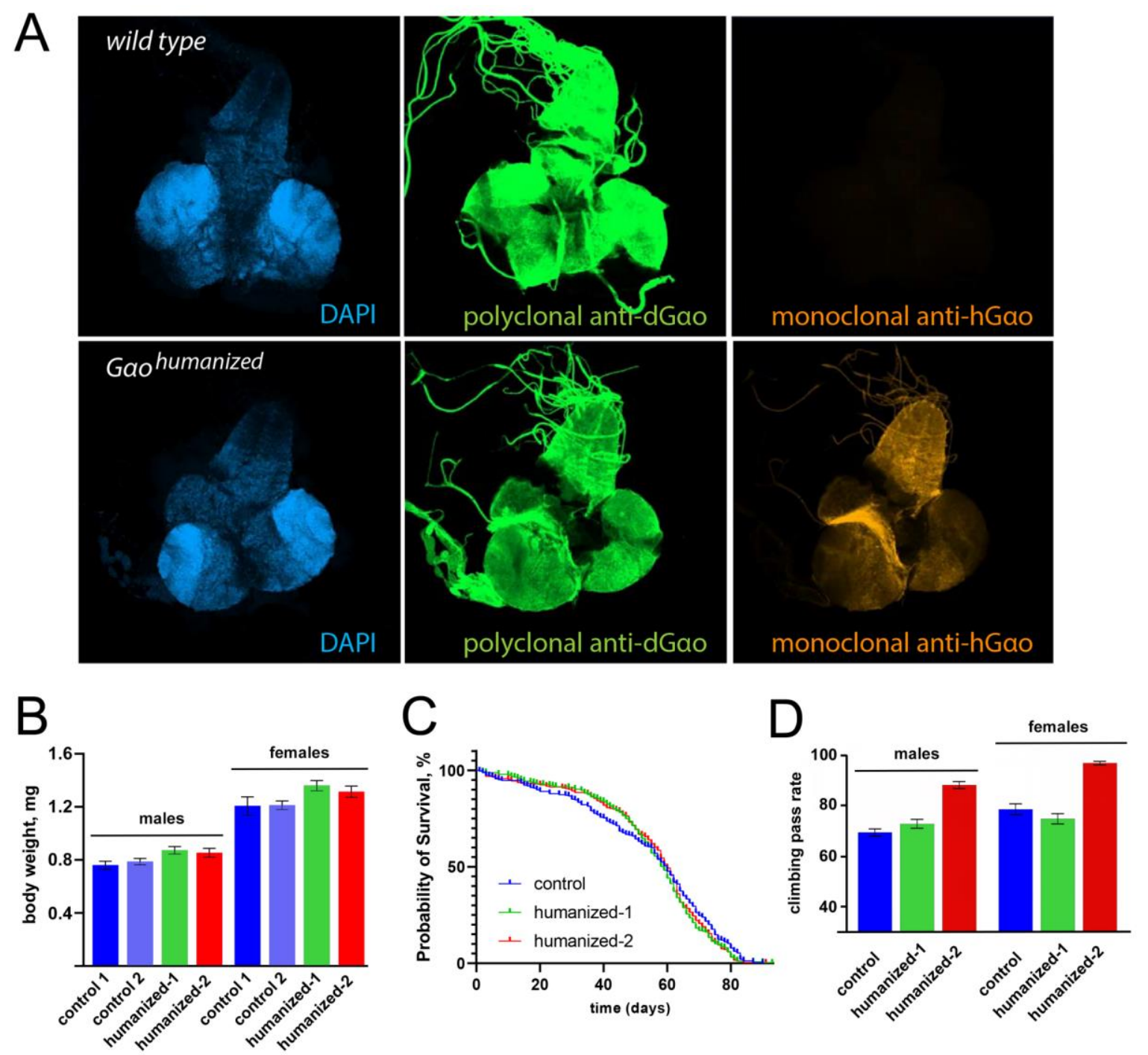

Figure 3. (A) Expression of humanized and wild-type G $\alpha_{0}$ in brains and ventral nerve cords of 3rd instar larvae. The upper panel represents a sample from wild-type larvae and the bottom panel-from dGao[humanized]. The immunostaining demonstrates specific recognition of the humanized protein (bottom right) with the monoclonal antibody recognizing hG $\alpha_{0}$; the polyclonal anti-dG $\alpha_{\mathrm{o}}$ antibodies, in contrast, recognize both $\mathrm{dG} \alpha_{\mathrm{o}}$ and $\mathrm{hG} \alpha_{\mathrm{o}}$ (the latter with a lower affinity as seen in the middle panels, which were recorded with identical confocal settings). (B) The body weight of the humanized flies is normal. The body weight in two control lines (the line used for initial injection is control 1 and an independent line is control 2) and the two homozygous humanized lines generated in our study was determined through measuring the weight of groups of fifty adult (2-3 days after hatching) male or female flies kept under non-crowding conditions; the individual fly body weight was then recalculated. Data are shown as mean \pm sd, $n=11$ to 13 groups of fifty flies. (C) The life span of 250 adult flies (125 males and 125 females; control animals were of the same genotype as 'control 1' in (B)) was determined during 93 days. (D) The locomotion behaviour of adult flies was measured in the negative geotaxis assay. Ten groups of 15 flies were measured three times for males, and the same for females, for each genotype. Data are shown as mean \pm sem, $n=30$. The T-test shows significant differences

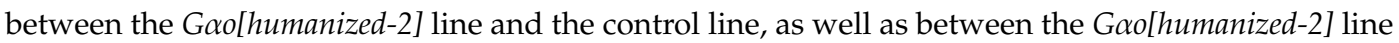
and the Goo[humanized-1] line, for both males and females ( $p$-values $<10^{-8}$ ), but not between the Goo[humanized-1] and control lines ( $p$-value > 0.1). 
The replacement of a model organism's protein-coding sequence with its human ortholog, preserving the endogenous gene expression regulators, represents an important tool to investigate the evolutionary and functional conservation of the gene of interest; this approach is particularly important for pathology-related genes [60]. A systematic investigation into the efficiency of gene humanization has been performed in yeast [61]. Despite several successful investigations in Drosophila [62,63], the fruit fly has not been systematically studied in this regard. Our study describes the first ever replacement of an endogenous Drosophila $\mathrm{G}$ protein with the orthologous human sequence. We find it remarkable that humanized G $\alpha$ o fully recapitulates the numerous Drosophila protein functions, resulting in phenotype-less, viable and fertile flies, having the normal life cycle, locomotory activity, and longevity. The resultant Drosophila strain humanized for the G $\alpha$ o gene can now be used to incorporate human mutations found in GNAO1 encephalopathy patients.

GNAO1 encephalopathies belong to the group of paediatric syndromes collectively referred to as developmental and epileptic encephalopathies (DEEs). Multiple DEEs have been modelled in Drosophila [54]. Of the genes implicated in human DEE, mutations in their Drosophila orthologues produce seizures or paralysis, as described, e.g., for the voltage-gated potassium channels Kv1.2 (Shaker in flies and KCNA2 in humans [64,65]) and Kv2.1 (Shaker cognate $b$ in flies and KCNB1 in humans [66,67]), the voltage-gated sodium channel (paralysis in flies and SCN1A in humans $[68,69]$ ), or the synaptic vesicle endocytosis regulator dynamin (shibire in flies and DNM1 in humans [70,71]). The successful establishment of a Drosophila model of a DEE can then be followed by two types of translational investigations: a suppressor-enhancer screening and a drug candidate screening. The first brings knowledge on the molecular partners of a disease protein, some of which may emerge as promising drug targets to ultimately develop a treatment of the human DEE. As an example, a suppressor-enhancer screening of the paralysis mutant identified gilgamesh to modify the manifestation of paralysis seizures; the human orthologue of gilgamesh is casein kinase gamma3, emerging as a potential new target to develop seizure therapeutics [72]. As a proof-of-concept for the second, several Drosophila epileptic mutants, including paralysis, showed amelioration of the phenotypes upon treatment with anticonvulsants such as gabapentin used to treat human epilepsy patients [73].

Despite the power of Drosophila genetics to model DEE and other neurological and non-neurological human diseases, to dissect the molecular aetiology of the disease and to screen for drug candidates [74], every model has its limitations. After all, Drosophila has significantly fewer neurons than human patients, and fewer genes as well. Although around $75 \%$ of pathology-related human genes have orthologues in Drosophila [75], the proteins they encode are not identical, which may constrain the way discoveries (especially discoveries of drug candidates) to be made on the Drosophila model can be translated to the human conditions. In this regard, humanization of the fruit fly orthologue prior to the establishment of the disease model can be viewed as a risk mitigation strategy.

Our work describes the first essential step towards the establishment of a Drosophila model of GNAO1 encephalopathies. The full power of Drosophila genetics and drug discovery tools available in this model organism [74,76] will then become accessible to uncover the molecular mechanisms of the aetiology of GNAO1 encephalopathy and to provide potential therapeutic leads to treat it. The progressive manner of this devastating disease affecting infants and the current lack of efficient treatment makes this approach highly desired.

Supplementary Materials: The following are available online at http://www.mdpi.com/2227-9059/8/10/395/s1.

Author Contributions: M.S. and V.L.K. drafted the manuscript. M.S., G.P.S. and V.L.K. provided intellectual input. All experiments were performed by M.S.; negative geotaxis assay was performed together with M.K. All authors have read and agreed to the published version of the manuscript.

Funding: The work was supported by the Swiss National Science Foundation grant \#31003A_175658 to VLK.

Acknowledgments: We thank the Drosophila facility of the Faculty of Medicine of the University of Geneva for providing the platform for our studies.

Conflicts of Interest: The authors declare no competing interests. 


\section{References}

1. Staley, K. Molecular mechanisms of epilepsy. Nat. Neurosci. 2015, 18, 367-372. [CrossRef]

2. Krook-Magnuson, E.; Soltesz, I. Beyond the hammer and the scalpel: Selective circuit control for the epilepsies. Nat. Neurosci. 2015, 18, 331-338. [CrossRef] [PubMed]

3. Ran, X.; Li, J.; Shao, Q.; Chen, H.; Lin, Z.; Sun, Z.S.; Wu, J. EpilepsyGene: A genetic resource for genes and mutations related to epilepsy. Nucleic Acids Res. 2015, 43, D893-D899. [CrossRef] [PubMed]

4. Noebels, J. Pathway-driven discovery of epilepsy genes. Nat. Neurosci. 2015, 18, 344-350. [CrossRef] [PubMed]

5. Grone, B.P.; Baraban, S.C. Animal models in epilepsy research: Legacies and new directions. Nat. Neurosci. 2015, 18, 339-343. [CrossRef]

6. McTague, A.; Howell, K.B.; Cross, J.H.; Kurian, M.A.; Scheffer, I.E. The genetic landscape of the epileptic encephalopathies of infancy and childhood. Lancet Neurol. 2016, 15, 304-316. [CrossRef]

7. Nakamura, K.; Kodera,H.; Akita, T.; Shiina, M.; Kato, M.; Hoshino, H.; Terashima, H.; Osaka, H.; Nakamura, S.; Tohyama, J.; et al. De Novo mutations in GNAO1, encoding a Galphao subunit of heterotrimeric G proteins, cause epileptic encephalopathy. Am. J. Hum. Genet. 2013, 93, 496-505. [CrossRef] [PubMed]

8. Schirinzi, T.; Garone, G.; Travaglini, L.; Vasco, G.; Galosi, S.; Rios, L.; Castiglioni, C.; Barassi, C.; Battaglia, D.; Gambardella, M.L.; et al. Phenomenology and clinical course of movement disorder in GNAO1 variants: Results from an analytical review. Parkinsonism. Relat. Disord. 2019, 61, 19-25. [CrossRef]

9. Menke, L.A.; Engelen, M.; Alders, M.; Odekerken, V.J.; Baas, F.; Cobben, J.M. Recurrent GNAO1 Mutations Associated With Developmental Delay and a Movement Disorder. J. Child. Neurol. 2016, 31, 1598-1601. [CrossRef]

10. Schorling, D.C.; Dietel, T.; Evers, C.; Hinderhofer, K.; Korinthenberg, R.; Ezzo, D.; Bonnemann, C.G.; Kirschner, J. Expanding Phenotype of De Novo Mutations in GNAO1: Four New Cases and Review of Literature. Neuropediatrics 2017. [CrossRef]

11. Talvik, I.; Moller, R.S.; Vaher, M.; Vaher, U.; Larsen, L.H.; Dahl, H.A.; Ilves, P.; Talvik, T. Clinical Phenotype of De Novo GNAO1 Mutation: Case Report and Review of Literature. Child. Neurol. Open. 2015, 2, 2329048X15583717. [CrossRef] [PubMed]

12. Hildebrand, M.S.; Jackson, V.E.; Scerri, T.S.; Van Reyk, O.; Coleman, M.; Braden, R.O.; Turner, S.; Rigbye, K.A.; Boys, A.; Barton, S.; et al. Severe childhood speech disorder: Gene discovery highlights transcriptional dysregulation. Neurology 2020, 94, e2148-e2167. [CrossRef] [PubMed]

13. Fredriksson, R.; Schioth, H.B. The repertoire of G-protein-coupled receptors in fully sequenced genomes. Mol. Pharmacol. 2005, 67, 1414-1425. [CrossRef] [PubMed]

14. Milligan, G.; Kostenis, E. Heterotrimeric G-proteins: A short history. Br. J. Pharmacol. 2006, 147 (Suppl. 1), S46-S55. [CrossRef]

15. Wettschureck, N.; Offermanns, S. Mammalian G proteins and their cell type specific functions. Physiol. Rev. 2005, 85, 1159-1204. [CrossRef]

16. Sternweis, P.C.; Robishaw, J.D. Isolation of two proteins with high affinity for guanine nucleotides from membranes of bovine brain. J. Biol. Chem. 1984, 259, 13806-13813.

17. Strathmann, M.; Simon, M.I. G protein diversity: A distinct class of alpha subunits is present in vertebrates and invertebrates. Proc. Natl. Acad. Sci. USA 1990, 87, 9113-9117. [CrossRef]

18. Wolfgang, W.J.; Quan, F.; Goldsmith, P.; Unson, C.; Spiegel, A.; Forte, M. Immunolocalization of G protein alpha-subunits in the Drosophila CNS. J. Neurosci. 1990, 10, 1014-1024. [CrossRef]

19. Greif, G.J.; Sodickson, D.L.; Bean, B.P.; Neer, E.J.; Mende, U. Altered regulation of potassium and calcium channels by $\mathrm{GABA}(\mathrm{B})$ and adenosine receptors in hippocampal neurons from mice lacking Galpha(o). J. Neurophysiol. 2000, 83, 1010-1018. [CrossRef]

20. Jiang, M.; Gold, M.S.; Boulay, G.; Spicher, K.; Peyton, M.; Brabet, P.; Srinivasan, Y.; Rudolph, U.; Ellison, G.; Birnbaumer, L. Multiple neurological abnormalities in mice deficient in the G protein Go. Proc. Natl. Acad. Sci. USA 1998, 95, 3269-3274. [CrossRef]

21. Campbell, V.; Berrow, N.; Dolphin, A.C. GABAB receptor modulation of Ca2+ currents in rat sensory neurones by the $G$ protein $G(0)$ : Antisense oligonucleotide studies. J. Physiol. 1993, 470, 1-11. [CrossRef]

22. Strathmann, M.; Wilkie, T.M.; Simon, M.I. Alternative splicing produces transcripts encoding two forms of the alpha subunit of GTP-binding protein Go. Proc. Natl. Acad. Sci. USA 1990, 87, 6477-6481. [CrossRef] 
23. Fremion, F.; Astier, M.; Zaffran, S.; Guillen, A.; Homburger, V.; Semeriva, M. The heterotrimeric protein Go is required for the formation of heart epithelium in Drosophila. J. Cell Biol. 1999, 145, 1063-1076. [CrossRef]

24. Valenzuela, D.; Han, X.; Mende, U.; Fankhauser, C.; Mashimo, H.; Huang, P.; Pfeffer, J.; Neer, E.J.; Fishman, M.C. $\mathrm{G}$ alpha(o) is necessary for muscarinic regulation of $\mathrm{Ca} 2+$ channels in mouse heart. Proc. Natl. Acad. Sci. USA 1997, 94, 1727-1732. [CrossRef]

25. Egger-Adam, D.; Katanaev, V.L. Trimeric G protein-dependent signaling by Frizzled receptors in animal development. Front. Biosci. 2008, 13, 4740-4755. [CrossRef]

26. Koval, A.; Purvanov, V.; Egger-Adam, D.; Katanaev, V.L. Yellow submarine of the Wnt/Frizzled signaling: Submerging from the $G$ protein harbor to the targets. Biochem. Pharmacol. 2011, 82, 1311-1319. [CrossRef]

27. Entschladen, F.; Zanker, K.S.; Powe, D.G. Heterotrimeric G protein signaling in cancer cells with regard to metastasis formation. Cell Cycle 2011, 10, 1086-1091. [CrossRef]

28. Song, L.; Yu, B.; Yang, Y.; Liang, J.; Zhang, Y.; Ding, L.; Wang, T.; Wan, X.; Yang, X.; Tang, J.; et al. Identification of functional cooperative mutations of GNAO1 in human acute lymphoblastic leukemia. Blood 2020. [CrossRef]

29. Milligan, G.; Streaty, R.A.; Gierschik, P.; Spiegel, A.M.; Klee, W.A. Development of opiate receptors and GTP-binding regulatory proteins in neonatal rat brain. J. Biol. Chem. 1987, 262, 8626-8630.

30. Strittmatter, S.M.; Valenzuela, D.; Kennedy, T.E.; Neer, E.J.; Fishman, M.C. G0 is a major growth cone protein subject to regulation by GAP-43. Nature 1990, 344, 836-841. [CrossRef]

31. Andreopoulos, S.; Li, P.P.; Warsh, J.J. Developmental expression of G alpha o and G alpha s isoforms in PC12 cells: Relationship to neurite outgrowth. Dev. Brain Res. 1995, 88, 30-36. [CrossRef]

32. Asano, T.; Morishita, R.; Sano, M.; Kato, K. The GTP-binding proteins, Go and Gi2, of neural cloned cells and their changes during differentiation. J. Neurochem. 1989, 53, 1195-1198. [CrossRef]

33. Zubiaur, M.; Neer, E.J. Nerve growth factor changes G protein levels and localization in PC12 cells. J. Neurosci. Res. 1993, 35, 207-217. [CrossRef]

34. Strittmatter, S.M.; Fishman, M.C.; Zhu, X.P. Activated mutants of the alpha subunit of G(o) promote an increased number of neurites per cell. J. Neurosci. 1994, 14, 2327-2338. [CrossRef]

35. Guillen, A.; Semeriva, M.; Bockaert, J.; Homburger, V. The transduction signalling protein Go during embryonic development of Drosophila melanogaster. Cell Signal. 1991, 3, 341-352. [CrossRef]

36. Wolfgang, W.J.; Quan, F.; Thambi, N.; Forte, M. Restricted spatial and temporal expression of G-protein alpha subunits during Drosophila embryogenesis. Development 1991, 113, 527-538.

37. Choi, J.M.; Kim, S.S.; Choi, C.I.; Cha, H.L.; Oh, H.H.; Ghil, S.; Lee, Y.D.; Birnbaumer, L.; Suh-Kim, H. Development of the main olfactory system and main olfactory epithelium-dependent male mating behavior are altered in Go-deficient mice. Proc. Natl. Acad. Sci. USA 2016. [CrossRef]

38. Lee, M.S.; Jun, D.H.; Hwang, C.I.; Park, S.S.; Kang, J.J.; Park, H.S.; Kim, J.; Kim, J.H.; Seo, J.S.; Park, W.Y. Selection of neural differentiation-specific genes by comparing profiles of random differentiation. Stem Cells 2006, 24, 1946-1955. [CrossRef]

39. Jiang, M.; Bajpayee, N.S. Molecular mechanisms of go signaling. Neurosignals 2009, 17, 23-41. [CrossRef]

40. Luchtenborg, A.M.; Solis, G.P.; Egger-Adam, D.; Koval, A.; Lin, C.; Blanchard, M.G.; Kellenberger, S.; Katanaev, V.L. Heterotrimeric Go protein links Wnt-Frizzled signaling with ankyrins to regulate the neuronal microtubule cytoskeleton. Development 2014, 141, 3399-3409. [CrossRef]

41. Lin, C.; Koval, A.; Tishchenko, S.; Gabdulkhakov, A.; Tin, U.; Solis, G.P.; Katanaev, V.L. Double suppression of the Galpha protein activity by RGS proteins. Mol. Cell 2014, 53, 663-671. [CrossRef]

42. Lin, C.; Katanaev, V.L. Kermit interacts with galphao, vang, and motor proteins in Drosophila planar cell polarity. PLoS ONE 2013, 8, e76885. [CrossRef]

43. Purvanov, V.; Koval, A.; Katanaev, V.L. A direct and functional interaction between Go and Rab5 during G protein-coupled receptor signaling. Sci. Signal. 2010, 3, ra65. [CrossRef]

44. Egger-Adam, D.; Katanaev, V.L. The trimeric G protein Go inflicts a double impact on axin in the Wnt/frizzled signaling pathway. Dev. Dyn. 2010, 239, 168-183. [CrossRef]

45. Kopein, D.; Katanaev, V.L. Drosophila GoLoco-protein pins is a target of Galpha(o)-mediated G protein-coupled receptor signaling. Mol. Biol. Cell 2009, 20, 3865-3877. [CrossRef]

46. Solis, G.P.; Bilousov, O.; Koval, A.; Luchtenborg, A.M.; Lin, C.; Katanaev, V.L. Golgi-Resident Galphao Promotes Protrusive Membrane Dynamics. Cell 2017, 170, 939-955 e924. [CrossRef] 
47. Solis, G.P.; Valnohova, J.; Alvarez, C.; Katanaev, V.L. Local and substrate-specific S-palmitoylation determines subcellular localization of G $\alpha 0$. bioRxiv 2020. [CrossRef]

48. Feng, H.; Sjogren, B.; Karaj, B.; Shaw, V.; Gezer, A.; Neubig, R.R. Movement disorder in GNAO1 encephalopathy associated with gain-of-function mutations. Neurology 2017, 89, 762-770. [CrossRef]

49. Bolus, H.; Crocker, K.; Boekhoff-Falk, G.; Chtarbanova, S. Modeling Neurodegenerative Disorders in Drosophila melanogaster. Int. J. Mol. Sci. 2020, 21, 3055. [CrossRef]

50. Bellen, H.J.; Wangler, M.F.; Yamamoto, S. The fruit fly at the interface of diagnosis and pathogenic mechanisms of rare and common human diseases. Hum. Mol. Genet. 2019, 28, R207-R214. [CrossRef]

51. Luchtenborg, A.M.; Katanaev, V.L. Lack of evidence of the interaction of the Abeta peptide with the Wnt signaling cascade in Drosophila models of Alzheimer's disease. Mol. Brain 2014, 7, 81. [CrossRef] [PubMed]

52. Katanaev, V.L.; Kryuchkov, M.V. The eye of Drosophila as a model system for studying intracellular signaling in ontogenesis and pathogenesis. Biochemistry (Mosc) 2011, 76, 1556-1581. [CrossRef] [PubMed]

53. Katanaev, V.L.; Kryuchkov, M.; Averkov, V.; Nikolaeva, K.; Klimova, N.; Khaustov, S.; Solis, G. HumanaFly: High-throughput transgenesis and expression of breast cancer transcripts in Drosophila eye discovers the RPS12-Wingless signaling axis. Unpublished manuscript.

54. Takai, A.; Yamaguchi, M.; Yoshida, H.; Chiyonobu, T. Investigating Developmental and Epileptic Encephalopathy Using Drosophila melanogaster. Int. J. Mol. Sci. 2020, 21, 6442. [CrossRef]

55. Gratz, S.J.; Ukken, F.P.; Rubinstein, C.D.; Thiede, G.; Donohue, L.K.; Cummings, A.M.; O'Connor-Giles, K.M. Highly specific and efficient CRISPR/Cas9-catalyzed homology-directed repair in Drosophila. Genetics 2014, 196, 961-971. [CrossRef]

56. Gloor, G.B.; Preston, C.R.; Johnson-Schlitz, D.M.; Nassif, N.A.; Phillis, R.W.; Benz, W.K.; Robertson, H.M.; Engels, W.R. Type I repressors of P element mobility. Genetics 1993, 135, 81-95.

57. Ali, Y.O.; Escala, W.; Ruan, K.; Zhai, R.G. Assaying locomotor, learning, and memory deficits in Drosophila models of neurodegeneration. J. Vis. Exp. 2011. [CrossRef]

58. Consortium, G.T. The Genotype-Tissue Expression (GTEx) project. Nat. Genet. 2013, 45, 580-585. [CrossRef]

59. Berghammer, A.J.; Klingler, M.; Wimmer, E.A. A universal marker for transgenic insects. Nature 1999, 402, 370-371. [CrossRef]

60. Takano-Shimizu-Kouno, T.; Ohsako, T. Humanized Flies and Resources for Cross-Species Study. Adv. Exp. Med. Biol. 2018, 1076, 277-288. [CrossRef]

61. Kachroo, A.H.; Laurent, J.M.; Yellman, C.M.; Meyer, A.G.; Wilke, C.O.; Marcotte, E.M. Evolution. Systematic humanization of yeast genes reveals conserved functions and genetic modularity. Science 2015, 348, 921-925. [CrossRef] [PubMed]

62. Wangler, M.F.; Yamamoto, S.; Chao, H.T.; Posey, J.E.; Westerfield, M.; Postlethwait, J.; Members of the Undiagnosed Diseases, N.; Hieter, P.; Boycott, K.M.; Campeau, P.M.; et al. Model Organisms Facilitate Rare Disease Diagnosis and Therapeutic Research. Genetics 2017, 207, 9-27. [CrossRef]

63. Chang, J.C.; Morton, D.B. Drosophila lines with mutant and wild type human TDP-43 replacing the endogenous gene reveals phosphorylation and ubiquitination in mutant lines in the absence of viability or lifespan defects. PLoS ONE 2017, 12, e0180828. [CrossRef]

64. Syrbe, S.; Hedrich, U.B.S.; Riesch, E.; Djemie, T.; Muller, S.; Moller, R.S.; Maher, B.; Hernandez-Hernandez, L.; Synofzik, M.; Caglayan, H.S.; et al. De novo loss- or gain-of-function mutations in KCNA2 cause epileptic encephalopathy. Nat. Genet. 2015, 47, 393-399. [CrossRef]

65. Papazian, D.M.; Schwarz, T.L.; Tempel, B.L.; Jan, Y.N.; Jan, L.Y. Cloning of genomic and complementary DNA from Shaker, a putative potassium channel gene from Drosophila. Science 1987, 237, 749-753. [CrossRef]

66. Ueda, A.; Wu, C.F. Distinct frequency-dependent regulation of nerve terminal excitability and synaptic transmission by IA and IK potassium channels revealed by Drosophila Shaker and Shab mutations. J. Neurosci. 2006, 26, 6238-6248. [CrossRef]

67. Calhoun, J.D.; Vanoye, C.G.; Kok, F.; George, A.L., Jr.; Kearney, J.A. Characterization of a KCNB1 variant associated with autism, intellectual disability, and epilepsy. Neurol. Genet. 2017, 3, e198. [CrossRef]

68. Suzuki, D.T.; Grigliatti, T.; Williamson, R. Temperature-sensitive mutations in Drosophila melanogaster. VII. A mutation (para-ts) causing reversible adult paralysis. Proc. Natl. Acad. Sci. USA 1971, 68, 890-893. [CrossRef]

69. Schutte, S.S.; Schutte, R.J.; Barragan, E.V.; O’Dowd, D.K. Model systems for studying cellular mechanisms of SCN1A-related epilepsy. J. Neurophysiol. 2016, 115, 1755-1766. [CrossRef] 
70. van der Bliek, A.M.; Meyerowitz, E.M. Dynamin-like protein encoded by the Drosophila shibire gene associated with vesicular traffic. Nature 1991, 351, 411-414. [CrossRef]

71. Nakashima, M.; Kouga, T.; Lourenco, C.M.; Shiina, M.; Goto, T.; Tsurusaki, Y.; Miyatake, S.; Miyake, N.; Saitsu, H.; Ogata, K.; et al. De novo DNM1 mutations in two cases of epileptic encephalopathy. Epilepsia 2016, 57, e18-e23. [CrossRef] [PubMed]

72. Howlett, I.C.; Rusan, Z.M.; Parker, L.; Tanouye, M.A. Drosophila as a model for intractable epilepsy: Gilgamesh suppresses seizures in para(bss1) heterozygote flies. G3 (Bethesda) 2013, 3, 1399-1407. [CrossRef] [PubMed]

73. Parker, L.; Howlett, I.C.; Rusan, Z.M.; Tanouye, M.A. Seizure and epilepsy: Studies of seizure disorders in Drosophila. Int. Rev. Neurobiol. 2011, 99, 1-21. [CrossRef]

74. Yamaguchi, M. (Ed.) Drosophila Models for Human Diseases; Springer: Singapore, 2018; Advances in Experimental Medicine and Biology; Volume 1076, pp. 1-308. ISBN 978-981-13-0528-3. [CrossRef]

75. Pandey, U.B.; Nichols, C.D. Human disease models in Drosophila melanogaster and the role of the fly in therapeutic drug discovery. Pharmacol. Rev. 2011, 63, 411-436. [CrossRef]

76. Sonoshita, M.; Cagan, R.L. Modeling Human Cancers in Drosophila. Curr Top. Dev. Biol. 2017, 121, $287-309$. [CrossRef]

(C) 2020 by the authors. Licensee MDPI, Basel, Switzerland. This article is an open access article distributed under the terms and conditions of the Creative Commons Attribution (CC BY) license (http://creativecommons.org/licenses/by/4.0/). 